\title{
PENINGKATAN KUALITAS PENGURUS DAN KUANTITAS ANGGOTA KOPERASI PADA KOPERASI WANITA PENANGGUNGAN KOTA MALANG
}

\author{
Sri Mulyani1) \\ 1)Institut Agama Islam Sunan Kalijogo Malang \\ 1)srimulyani@iaiskjmalang.ac.id
}

\begin{abstract}
Abstrak: Koperasi merupakan soko guru perekonomian bangsa. Sebagai soko guru perekonomian bangsa, maka koperasi harus terus dikembangkan sehingga mempunyai daya saing. Untuk berdaya saing, salah satu hal yang sangat penting bagi organisasi adalah kualitas SDM. Koperasi Wanita Penanggungan merupakan salah satu koperasi wanita yang ada di Kota Malang yang produktif. Untuk meningkatkan daya saing dan supaya Kopwan Penanggungan tersebut bisa terus berkesinambungan maka perlu diadakan suatu program peningkatan kualitas pengurus dan kuantitas anggotanya. Tujuan dari kegiatan pengabdian ini adalah untuk mendeskripsikan dan menganalisis tentang bagaimana strategi peningkatan kualitas pengurus dan peningkatan kuantitas jumlah anggota di Koperasi Wanita Penanggungan Kota Malang. Metode dan pendekatan yang digunakan didalam kegiatan pengabdian ini adalah dengan pendekatan metode ceramah, partisipatif, pendekatan kelompok, metode diskusi/Forum Group Discussion (FGD) dan pendampingan. Hasil dari kegiatan pengabdian ini bahwa peningkatan kualitas pengurus Kopwan Penanggungan bisa dilakukan dengan beberapa langkah antara lain mengokohkan kepemimpinan, meningkatkan pelayanan pengurus kepada anggota, meningkatkan kredibilitas pengurus Kopwan Penanggungan, mengadakan pelatihan pelaksanaan pembukuan dan laporan keuangan sistemkomputerisasi, mengadakan pelatihan pengemasan dan marketing produk-produk anggota, melakukan pendampingan secara rutin, evaluasi dan monitoring terhadap program yang dilaksanakan di Kopwan Penanggungan. Sedangkan untuk meningkatkan kuantitas anggota koperasi, maka salah satau langkah bisa dilakukan adalah dengan menanamkan kepercayaan (trust) anggota kepada para pengurus Kopwan Penanggungan melalui pengelolaan Kopwan yang profesional, kredibel dan transparan.
\end{abstract}

Kata Kunci: Kualitas pengurus, Kuantitas Anggota, Koperasi Wanita

\begin{abstract}
Cooperatives are the pillars of the nation's economy. As the pillars of the nation's economy, cooperatives must continue to be developed so that they have competitiveness. To be competitive, one of the most important things for an organization is the quality of human resources. The Penanggungan Women's Cooperative is one of the productive women's cooperatives in Malang. In order to improve competitiveness and so that the Kopwan Penanggungan can be sustainable, it is necessary to hold a program to improve the quality of the management and the quantity of its members. The purpose of this community service activity is to describe and analyze how the strategy for improving the
\end{abstract}


quality of the management and increasing the number of members in the Penanggungan Women's Cooperative in Malang City. The methods and approaches used in this service are lecture, participatory, group approaches, discussion methods / Forum Group Discussion (FGD) and mentoring. The result of this service activity is that improving the quality of Kopwan Penanggungan administrators can be done in several steps, including strengthening leadership, improving management services to members, increasing the credibility of Kopwan Penanggungan administrators, holding training in the implementation of bookkeeping and computerized financial reports, holding training on packaging and marketing of products. members, provide regular assistance, evaluation and monitoring of programs implemented at Kopwan Penanggungan. Meanwhile, to increase the quantity of cooperative members, one step can be taken is to instill trust in members of the Kopwan Penanggungan management through professional, credible and transparent Kopwan management.

Keywords: Quality of management, Quantity of Members, Women's Cooperative

\section{PENDAHULUAN}

Sumber Daya Manusia (SDM) merupakan salah satu unsur yang berperan dalam kemajuan suatu organisasi dalam mencapai tujuannya karena SDM adalah satu-satunya sumber daya yang memiliki akal, perasaan, keinginan, keterampilan, pengetahuan, dorongan, daya, karya. Secara teoritis dan empiris, keberhasilan organisasi dalam menjalankan fungsinya merupakan kontribusi langsung dari perilaku pegawainya. ${ }^{1}$ Sehingga setiap karyawan perlu meningkatkan kompetensinya agar mampu bersaing dalam perkembangan bisnis. Keberadaan organisasi koperasi di Indonesia memiliki landasan yang tertuang dalam Undang-Undang Dasar 1945 khusus-nya pasal 33, selanjutnya dijabarkan lebih lanjut dalam UU No 12 Tahun 1967, tentang pokok-pokok perkoperasian dan disempurnakan lagi dengan UU Nomor 25 tahun 1992, sebagai soko guru perekonomian Indonesia bahwa Koperasi adalah badan usaha yang beranggotakan orang-seorang atau badan hukum koperasi dengan melandaskan kegiatannya berdasarkan prinsip koperasi sekaligus sebagai gerakan ekonomi rakyat yang berdasar atas asas kekeluargaan (Undang-Undang Nomor 25, 1992).

Berbagai jenis Koperasi yang ada di Indonesia salah satunya adalah Koperasi Wanita (KOPWAN) dimana keberhasilan Koperasi Wanita (KOPWAN) tidak dapat

\footnotetext{
1 Dana Krisfandi, "Pengaruh Kualitas Pelayanan Terhadap Kinerja Pengurus Koperasi Unit Desa (KUD) Sari Usaha Tani Desa Kota Baru Kabupaten Rokan Hulu” (Universitas Pasir Pangaraian, 2015).
} 
dilepaskan dari konsep kepercayaan (trust) dari anggota kepada Pengurus dan sebaliknya. Dilihat dari aspek ekonomi, Koperasi Wanita bisa berperan untuk meningkatkan kesejahteraan keluarga pada khususnya, kesejahteraan masyarakat pada umumnya. Koperasi Wanita juga bisa dijadikan wadah sebagai lembaga permberdayaan dan aktuliasasi diri bagi para wanita sehingga para wanita tidak hanya disibukkan dalam kegiatan domestik saja. Dengan demikian urgensi dari Koperasi Wanita antara lain adalah:

1. Wanita mempunyai beberapa ketrampilan yang bisa dikembangkan baik ketrampilan yang terkait dengan kerajinan tangan maupun ketrampilan lainnya.

2. Wanita berperan didalam peningkatan kesejahteraan keluarga.

3. Koperasi Wanita dibutuhkan bagi wanita sebagai wadah untuk pemberdayaan dan aktualisasi diri bagi kaum wanita.

Untuk bisa tumbuh dan berkembang dengan baik, Koperasi Wanita memerlukan tatakelola (Good Governance) yang bagus yang dilakukan oleh pengurusnya dan dukungan atau partisipasi dari para anggotanya. Oleh karena itu diperlukan program-program yang bisa mendorong peningkatan kualitas pengurus dan kuantitas anggota Koperasi Wanita.

Koperasi Wanita Penanggungan yang ada di Kecamatan Klojen Kota Malang merupakan salah satu Kopwan yang produktif. Koperasi Wanita Penanggungan ini sudah memiliki produk unggulan yang merupakan hasil karya dari para anggota yaitu berupa gerabah. Selain itu Kopwan Penanggungan ini juga menyediakan jasa simpan pinjam bagi para anggotanya untuk bisa meningkatkan produksinya. Oleh karena itu, keberadaan Kopwan Penanggungan ini perlu mendapatkan pendampingan baik bagi pengurus maupun bagi anggotanya agar Kopwan Penanggungan ini bisa semakin berkembang baik secara kualitas maupun kuantitas jumlah anggotanya. Dari uraian diatas, maka dapat dibuat rumusan masalah yaitu : "Bagaimana strategi peningkatan kualitas pengurus dan kuantitas jumlah anggota Koperasi Wanita Penanggungan Kecamatan Klojen Kota Malang ?". Kegiatan Pengabdian Kepada Masyarakat ini bertujuan untuk mendeskripsikan dan menganalisis tentang bagaimana strategi peningkatan kualitas pengurus dan peningkatan kuantitas jumlah anggota di Koperasi Wanita Penanggungan Kota Malang.

\section{METODE PELAKSANAAN KEGIATAN}


Metode pelaksanaan kegiatan ini dilakukan dengan pendekatan metode ceramah, partisipatif, pendekatan kelompok, metode diskusi/Forum Group Discussion (FGD) dan pendampingan. Metode ceramah dilakukan dengan tujuan untuk memberikan pemahaman yang lebih detail kepada pengurus dan anggota koperasi tentang pentinganya koperasi wanita, pentingnya peningkatan kualitas pengurus koperasi dan pentingnya kuatitas anggota koperasi. Pendekatan partisipatif digunakan agar pengurus koperasi dan anggota koperasi bisa berpartisipasi secara aktif terhadap semua kegiatan mulai dari awal sampai akhir. Sedangkan pendekatan kelompok merupakan pendekatan yang digunakan untuk melaksanakan program lanjutan yaitu untuk melaksanakan pelatihan pembukuan dan administrasi pada tahap awal, pelatihan manajemen keuangan koperasi, dan pelatihan pengembangan produk.

\section{PEMBAHASAN DAN HASIL KEGIATAN}

\subsection{Pengertian Koperasi dan Koperasi Sebagai Soko Guru Perekonomian}

Koperasi berasal dari kata "cooperative" yang artinya adalah bekerja bersama. Adapun pengertian Koperasi yaitu suatu organisasi yang terdiri dari kumpulan orang dengan kepentingan ekonomi yang sama dimana orang-orang tersebut berupaya memenuhi kepentingannya melalui kerjasama mereka dalam mengelola dan mengawasi organisasinya sehingga perusahaan/organisasinya dapat memberikan pelayanan ekonomi kepada orang-orang tersebut.2 Sesuai dengan Undang-Undang Dasar (UUD)1945 Pasal 33 ayat 1 yang menyatakan bahwa perekonomian disusun sebagai usaha bersama berdasarkan asas kekeluargaan. Koperasi merupaka soko guru perekonomian bangsa sesuai dengan kesepakatan Kongres Koperasi Pertama tanggal 12 Juli 1947 di Tasikmalaya yang menyatakan bahwa asas koperasi Indonesia adalah kekeluargaan dan gotong royong. ${ }^{3}$

\subsection{Gambaran Umum Koperasi Wanita Penanggungan}

\footnotetext{
2 Mailani Ineu, Peran Koperasi Dalam Ekonomi Kerakyatan (Jakarta: Universitas Gunadharma, 2011). ${ }^{3}$ Nurul Mubarok, Sinta Ardhillatul Jannah, and Septi Laksanawati, "Analisis Identifikasi Masalah Utama Koperasi Di Kabupaten Banyuasin Dalam Mewujudkan Kesejahteraan Anggota," I-ECONOMICS: A Research Journal on Islamic Economics 4, no. 2 (2019): 194-213, https://doi.org/10.19109/ieconomics.v4i2.3039.
} 
Koperasi Wanita Penanggungan merupakan koperasi yang didirikan oleh TP PKK Kelurahan Penanggungan. Secara administratif, pembinaan Kopwan Penanggungan berada dibawah Kepala Seksi Pemerintahan, Ketentraman dan Ketertiban Umum yang mempunyai tugas melakukan pembinaan dan pengembangan serta pemantauan kegiatan perindustrian, perdagangan, kepariwisataan, perkoperasian, usaha kecil menengah, dan golongan ekonomi lemah di wilayah kerjanya. Seperti Koperasi pada umumnya, Kopwan Penanggungan mempunyai sumber pemasukan dari para anggotnya yaitu berupa simpanan pokok, simpanan wajib dan simpanan sukarela. Dari pemasukan yang terkumpul dari para anggotanya, modal yang terkumpul salah satunya digunakan untuk program pemberdayaan anggota yaitu untuk memproduksi gerabah, souvenir yang terbuat dari keramik. Produk tersebut merupakan produk unggulan yang diproduksi oleh Kopwan Penanggungan. Pada awalnya produk tersebut hanya dipasarkan di kelurahan penanggungan saja dengan metode pemasaran tradisional yaitu dari mulut ke mulut. Namun, pada saat ini produk-produk tersebut sudah dipasarkan diluar Kelurahan Penanggungan bahkan juga luar Kota Malang.

\subsection{Gambaran Kegiatan}

Kegiatan ini dilakukan pada hari Selasa, 31 April 2019 mulai Pukul 09.00-Pukul 15.00 WIB bertempat di Kantor Kelurahan Penanggungan Kecamatan Klojen Kota Malang. Kegiatan ini dilakukan dengan menggunakan metode ceramah dan dilanjutkan dengan FGD serta pendampingan kepada pengurus dan anggota Kopwan Penanggungan. Kegiatan ini meliputi:

1. Ceramah

Di dalam ceramah yang diberikan, narasumber menyampaikan materi tentang peningkatan kualitas pengurus dan kuantitas anggota Kopwan Penanggungan. Di dalam ceramah tersebut juga dibuka sesi tanya jawab yang berfungsi untuk mengetahui permasalahan-permasalahan apa yang dihadapi oleh Kopwan Penanggungan.

2. Focus Group Discusion (FGD) 
FGD ini merupakan FGD terarah dilakukan dengan membentuk kelompok diskusi. Setiap kelompok terdiri atas 7-8 orang. Hal ini dilakukan untuk memperoleh informasi, saran dan masukan dari para anggoita FGD. FGD ini dilakukan dengan cara mengelompokkan para peserta sesuai dengan bidanganya. Di Kopwan Penanggungan sendiri ada beberapa bagian yang menangani produksi barangbarang keramik, ada bagian yang menangani pemasaran produk serta ada yang menangani keuangan hasil penjualan. Oleh karena itu FGD dilakukan dengan mengelompokkan sesuai bagian-bagian tersebut. Hal ini agar masalah yang ada di tiap bagian bisa diakomodir dan bisa diselesaikan dengan baik.

3. Pendampingan

Dalam acara ini dihadiri oleh pengurus dan anggota Koperasi Wanita Kelurahan Penanggungan. Kopwan Penanggungan merupakan koperasi yang didirikan sebagai wadah untuk beraktualisasi khususnya bagi ibu-ibu PKK yang ada di Kelurahan Penanggungan. Berdasarkan wawancara yang dilakukan peneliti kepada Ketua Kopwan Penanggungan yaitu Titik Sumartini bahwa meskipun tergololong masih baru berdiri, Kopwan Penanggungan memiliki beberapa keunggulan yaitu adanya kekompakan dari para anggotanya. Selain itu anggota Kopwan juga mempunyai keahlian didalam membuat kerajinan tangan yaitu salah satunya adalah berbagai kerajinan keramik. Kekompakan dan semangat dari para anggota menjadi suatu aset atau modal sosial yang perlu dikembangkan. Namun, selain keunggulan yang dimiliki Kopwan Penanggungan juga mempunyai kelemahan yaitu diantaranya adalah tentang manajerial atau pengelolaan administrasi koperasi yang masih memerlukan penyempurnaan seperti penyusunan laporan keuangan koperasi.

\subsection{Hasil Kegiatan}

\section{Peningkatan Kualitas Pengurus Koperasi Wanita}

Pengurus yang berkualitas adalah pengurus yang mempunyai kinerja yang bagus didalam memberikan pelayanan kepada anggotanya. Beberapa hal yang 
bisa digunakan untuk mengukur kinerja pengurus koperasi antara lain bisa dilihat dari 4 :

1. Kualitas kerja

2. Ketepatan waktu

3. Inisiatif

4. Kemampuan

5. Komunikasi

Terdapat 3 hal yang perlu diperhatikan di dalam peningkatan kualitas koperasi agar bisa mempunyai daya saing antara lain yaitu kelembagaan, SDM dan permodalan. $^{5}$ Aspek SDM merupakan aspek yang sangat penting untuk diperhatikan dalam rangka meningkatkan nilai (value) koperasi karena hal tersebut terkait dengan fungsi pengurus, fungsi pengawas, fungsi manajer serta karyawan koperasi. Ketidakjelasan didalam pelaksanaan fungsi SDM bisa berdampak pada penyalahgunaan jabatan atau wewenang untuk mendapatkan keuntungan pribadi. 6

Dasar hukum koperasi :

UU No.25 th 1992 tentang Perkoperasian Pasal 44 ayat 2

PP No. 9 th 1995 tentang Pelaksanaan Kegiatan Usaha Simpan Pinjam Oleh Koperasi Pasal 12 ayat 1

Permen No.15 th 2015 tentang Usaha Simpan Pinjam oleh Koperasi Prinsip-Prinsip Peroperasian:

1) keanggotaan bersifat sukarela dan terbuka;

2) pengelolaan dilakukan secara demokratis;

3) pembagian sisa hasil usaha dilakukan secara adil sebanding dengan besarnya jasa usaha masing-masing anggota;

4) pemberian balas jasa yang terbatas terhadap modal;

5) kemandirian.

${ }^{4}$ Krisfandi, "Pengaruh Kualitas Pelayanan Terhadap Kinerja Pengurus Koperasi Unit Desa (KUD) Sari Usaha Tani Desa Kota Baru Kabupaten Rokan Hulu." Hal 2

${ }^{5}$ Baswir Revrisond, Koperasi Indonesia (Yogyakarta: BPFE, 2000).

6 Yuan Arsinta, "Strategi Peningkatan Kualitas Kelembagaan Koperasi Pada Dinas Koperasi Kota Semarang," Economic Education Analysis Journal 7, no. 1 (2018): 18-23. 
Tujuan Koperasi

a. Meningkatkan program pemberdayaan ekonomi, khususnya di kalangan usaha mikro, kecil menengah dan koperasi melalui sistem syari'ah.

b. Mendorong kehidupan ekonomi syari'ah dalam kegiatan usaha mikro, kecil dan menengah khususnya dan ekonomi indonesia pada umumnya.

c. Meningkatkan semangat dan peran anggota masyarakat dalam kegiatan KSP.

d. Menggerakkan usaha sektor riil anggotanya

e. Menumbuhkan wira usaha baru

f. Meningkatkan skala usaha anggota

Dalam rangka meningkatkan kualitas pengurus Kopwan Penanggungan maka halhal yang perlu dilakukan adalah:

1) Melakukan FGD secara rutin diantara pengurus dan anggota Kopwan Penangunggan yaitu disepakatai dua minggu sekali.

2) Mengokohkan kepemimpinan di Kopwan Penanggungan.

3) Meningkatkan pelayanan pengurus Kopwan Penanggungan kepada anggota Kopwan Penanggungan.

4) Meningkatkan kredibilitas pengurus Kopwan Penanggungan.

5) Mengadakan pelatihan pelaksanaan pembukuan dan laporan keuangan sistemkomputerisasi

6) Mengadakan pelatihan pengemasan dan marketing produk-produk Kopwan Penanggungan

7) Melakukan pendampingan secara rutin.

8) Melakukan evaluasi dan monitoring terhadap program yang dilaksanakan di Kopwan Penanggungan.

\section{Peningkatan Kuantitas Anggota Koperasi Wanita}

Sedangkan peningkatan kuantitas anggota Kopwan Penanggungan dilakukan dengan cara:

a) Menjaga hubungan yang baik antara pengurus dan anggota Kopwan Penanggungan. 
b) Pengurus terbuka dalam komunikasi dan informasi kepada para anggota Kopwan Penanggungan.

c) Menanamkan kepercayaan anggota kepada para pengurus Kopwan Penanggungan melalui pengelolaan Kopwan yang profesional, kredibel dan transparan.

d) Memberikan berbagai pelatihan yang berkualitas kepada para anggota Kopwan Penanggungan sehingga bisa menarik warga untuk masuk menjadi anggota Kopwan Penanggungan.

e) Pengurus memberikan laporan pengelolaan Kopwan secara terbuka.
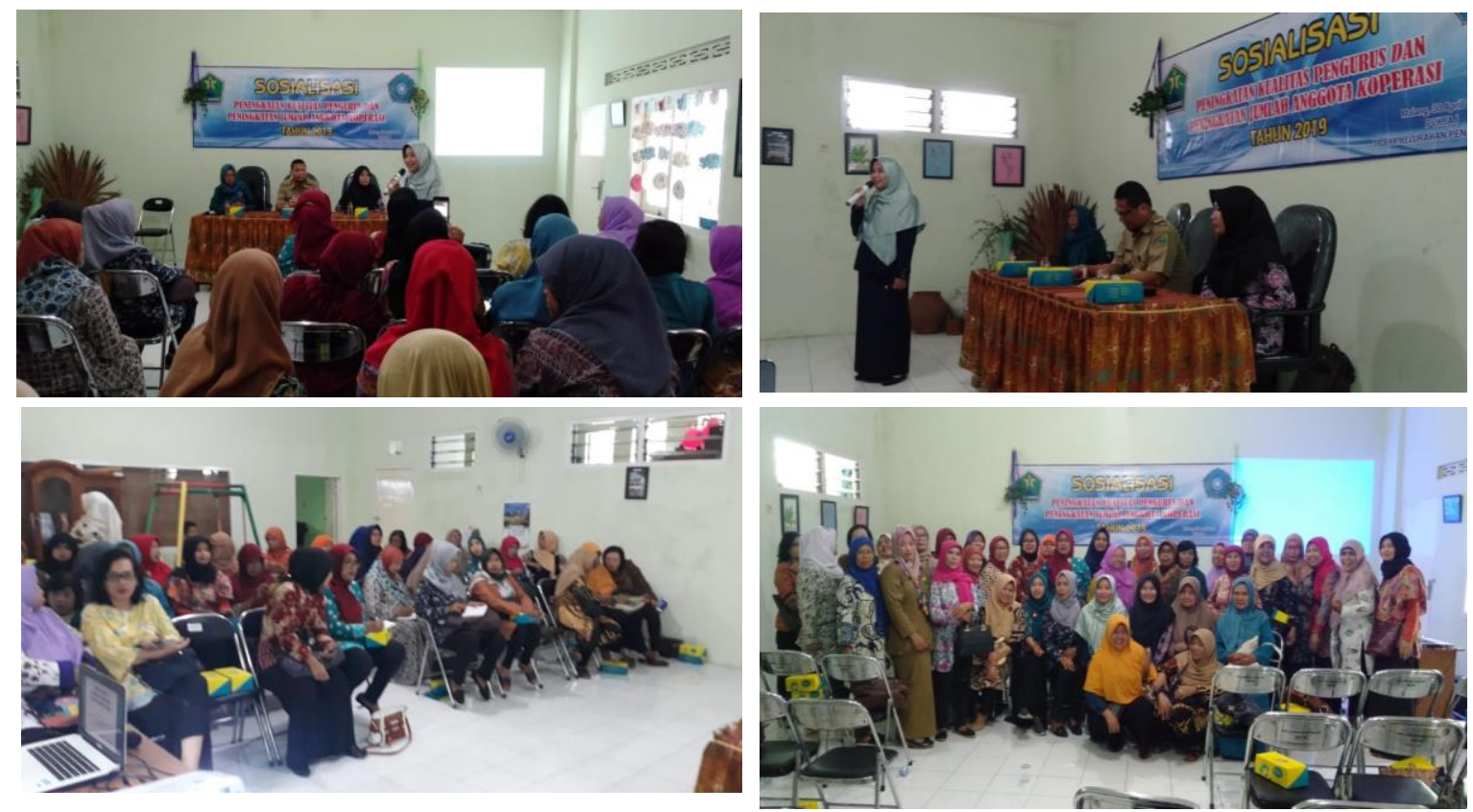

Gambar 1.

Pelaksanaan Kegiatan

\section{PENUTUP}

\section{Kesimpulan}

Dari uraian diatas maka dapat diambil kesimpulan:

1. Kegiatan pengabdian masyarakat di Kopwan Kelurahan Penanggungan Kecamatan Klojen dilakukan melalui tiga tahap yaitu ceramah berupa pemberian materi, pembentukan FGD dan pendampingan. 
2. Peningkatan kualitas pengurus Koperasi Wanita Kelurahan Penanggungan Kecamatan Klojen dilakukan dengan :

a) Melakukan FGD secara rutin diantara pengurus dan anggota Kopwan Penangunggan yaitu disepakatai dua minggu sekali.

b) Mengokohkan kepemimpinan di Kopwan Penanggungan.

c) Meningkatkan pelayanan pengurus Kopwan Penanggungan kepada anggota Kopwan Penanggungan.

d) Meningkatkan kredibilitas pengurus Kopwan Penanggungan.

e) Mengadakan pelatihan pelaksanaan pembukuan dan laporan keuangan sistemkomputerisasi

f) Mengadakan pelatihan pengemasan dan marketing produk-produk anggota Kopwan Penanggungan

g) Melakukan pendampingan secara rutin.

h) Melakukan evaluasi dan monitoring terhadap program yang dilaksanakan di Kopwan Penanggungan.

3. Peningkatan kuantitas anggota Koperasi Wanita Kelurahan Penanggungan Kecamatan Klojen dilakukan dengan cara :

a) Menjaga hubungan yang baik antara pengurus dan anggota Kopwan Penanggungan.

b) Pengurus terbuka dalam komunikasi dan informasi kepada para anggota Kopwan Penanggungan.

c) Menanamkan kepercayaan (trust) anggota kepada para pengurus Kopwan Penanggungan melalui pengelolaan Kopwan yang profesional, kredibel dan transparan.

d) Memberikan berbagai pelatihan yang berkualitas kepada para anggota Kopwan Penanggungan sehingga bisa menarik warga untuk masuk menjadi anggota Kopwan Penanggungan.

e) Pengurus memberikan laporan pengelolaan Kopwan secara terbuka.

\section{Saran}


Saran dari kegiatan ini adalah :

1. Perlu adanya motivasi yang tinggi, dan pengawalan dari pengurus Koperasi Wanita Penanggungan dan dinas terkait untuk lebih berkembanganya Kopwan Penangguan khususnya didalam pengembangan produk-produk kerajinan anggota Koperasi.

2. Perlu adanya koordinasi rutin antara pengurus dan anggota koperasi sehingga bisa meningkatkan pemahaman bersaman dalam rangka pengembangan Kopwan Penanggungan.

3. Perlu adanya evaluasi terkait program-program yang telah dilaksanakan termasuk kaitannya kegiatan produksi, pengemasan dan pemasaran dari produk yang dihasilkan Kopwan Penanggungan.

4. Pelaporan keuangan dan basis data anggota koperasi perlu dilakukan dengan menggunakan sistem yang sudah terkomputerisasi. 


\section{DAFTAR PUSTAKA}

Arsinta, Yuan. "Strategi Peningkatan Kualitas Kelembagaan Koperasi Pada Dinas Koperasi Kota Semarang." Economic Education Analysis Journal 7, no. 1 (2018): 18-23.

Ineu, Mailani. Peran Koperasi Dalam Ekonomi Kerakyatan. Jakarta: Universitas Gunadharma, 2011.

Krisfandi, Dana. "Pengaruh Kualitas Pelayanan Terhadap Kinerja Pengurus Koperasi Unit Desa (KUD) Sari Usaha Tani Desa Kota Baru Kabupaten Rokan Hulu." Universitas Pasir Pangaraian, 2015.

Mubarok, Nurul, Sinta Ardhillatul Jannah, and Septi Laksanawati. "Analisis Identifikasi Masalah Utama Koperasi Di Kabupaten Banyuasin Dalam Mewujudkan Kesejahteraan Anggota." I-ECONOMICS: A Research Journal on Islamic Economics 4, no. 2 (2019): 194213. https://doi.org/10.19109/ieconomics.v4i2.3039.

Revrisond, Baswir. Koperasi Indonesia. Yogyakarta: BPFE, 2000.

Wasiaturrahma. Peningkatan Kinerja Koperasi Melalui Pendampingan Manajemen Keuangan pada Koperasi 64 Bahari Surabaya. Jurnal Berdaya Mandiri, Vol 2 No. 1 Tahun 2020. 